\title{
The Undrainable Post-Traumatic Right Massive Haemothorax
}

\author{
Anthony Adimonye*, Arthur Cotton and James Jenkins \\ Department of Surgery, Gloucestershire Hospitals NHS Foundation Trust, UK \\ Received: December 06, 2017; Published: December 14, 2017 \\ *Corresponding author: Anthony Adimonye, Department of Surgery, Gloucestershire Hospitals NHS Foundation Trust, UK; \\ Email: anthony2407@gmail.com
}

Abstract

Traumatic right diaphragmatic hernias are uncommon and frequently missed. We present an interesting case of a patient initially thought to have clinical and radiological signs of a right massive haemothorax that was actually a large right diaphragmatic hernia, which was managed surgically.

\section{Introduction}

Diaphragmatic injuries related to thoraco-abdominal trauma are rare, with an incidence of $0.8-5 \%$ [1]. Due to coexisting injuries, small herniation and the silent nature of diaphragmatic ruptures, the diagnosis can sometimes be missed in the acute phase, and may present later with obstructive symptoms due to incarcerated organs in the diaphragmatic defect [2]. Right sided diaphragmatic herniation is infrequent due to protection by the liver and the congenitally stronger, right hemi-diaphragm $[1,3]$. This case report discusses an adult patient who was diagnosed to have right-sided diaphragmatic rupture and hepatothorax, acutely following a road traffic accident.

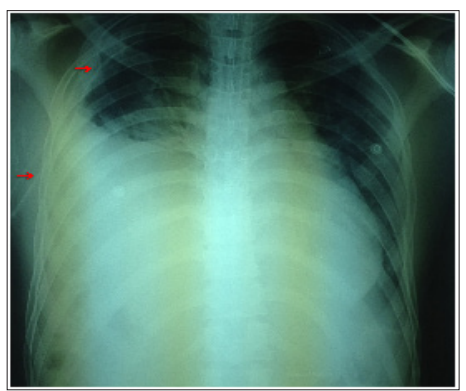

Figure 1: Chest radiograph showing marked elevation of the right hemi-diaphragm with an in-situ intercostal chest drain (red arrows).

\section{Case Report}

A 26 year old man was admitted to accident and emergency following a road traffic accident. On admission the patient was distressed, dyspnoeic and hypotensive. Initial primary survey revealed a right massive haemothorax, a pelvic fracture, a right femoral fracture and a left tibial fracture (Figure 1). Despite initial resuscitation and chest drain insertion the patient remained in respiratory distress with a puzzling and seemingly undrainable haemothorax. A placement of a second intercostal chest drain was queried, due to the position of the first drain 'above the massive haemothorax. Before this, a review of the gentleman was carried out to consolidate or refute the diagnosis of a massive haemothorax.

This evaluation revealed the trachea was central and not displaced, and an ultrasound scan of the right side of his chest wall revealed a hepatothorax. Hence, a diagnosis of a traumatic right diaphragmatic rupture with herniation of the liver was proposed. And a second chest drain insertion with potentially catastrophic consequences was obviated. He underwent emergency laparotomy, which confirmed this diagnosis and his liver was reduced back in to the abdominal cavity and the diaphragmatic defect was closed. He was subsequently admitted to ITU for airway management and optimization for further orthopaedic intervention.

\section{Learning Points/Take Home Messages}

i. A thorough examination and patient reassessment is crucial in a major trauma setting especially if your initial diagnosis does not fit the clinical picture.

ii. Traumatic diaphragmatic rupture should be considered and a high index of suspicion maintained in patients with multiple injuries and an abnormal chest x-ray.

iii. Radiological investigations are helpful in reaching a clear diagnosis.

\section{References}

1. Aymerich T, Artigas MG, Monfort JM, Hugas M (2000) Effect of sausage ingredients and additives on Cuban. Journal of Agricultural Science 46: 8. 
2. Bali V, Panesar PS, Bera MB (2011) Isolation, screening and evaluation of antimicrobial activity of potential bacteriocin producing lactic acid bacteria isolate. Microbiol J 1: 113-119.

3. Ogunbanwo ST, Sanni AI, Onilude AA (2003) Characterization of Bacteriocin Produced by Lactobacillus plantarum F1 and Lactobacillus brevis OG1. African Journal of Biotechnology 2(8): 219- 227.

4. Yodoamijoyo RM, Tirza Z, Harastuti Tomomatsu A Matsuyama A, Hosono A Antimicrobiol activities of Lactic acid bacteria strains. J dairy food Sci 32: 7-14.

5. Samelis J, Maurogenakis F, Metaxopoulos J (1994) Characterization of lactic acid bacteria isolated from naturally fermented Greek dry salami. Int J Food Microbiol 23(2): 179-196.

6. Shuhaimi M (2003) Species classification and molecular studies of bile salt hydrolase gene in Bifidobacterium spp. Doctor of philosophy. University Putra Malaysia 1-174.
7. Patterson JA, Burkholder KM (2003) Application of prebiotics and probiotics in poultry production. Poult Sci 82(4): 627.

8. Ben CP, Beula A, Nirmala Devi S (2012) Production and Partial Purification of Lactocin produced from Lactobacillus lactis and its Bactericidal activity against Food spoiling bacteria. ISCA Journal of Biological Sciences 1(3): 49-53.

9. Lasta S, Ouzar H (2012) Lactocin LC14, a New Bacteriocin Produced by Lactococcus lactis BMG6.14: Isolation. Purification and Partial Characterization P 3(2): 133-13.

10. Laemmli UK (1970) Cleavage of structural proteins during the assembly of the head of bacteriophage T. 4 Natures 277 (5259): 680-685.

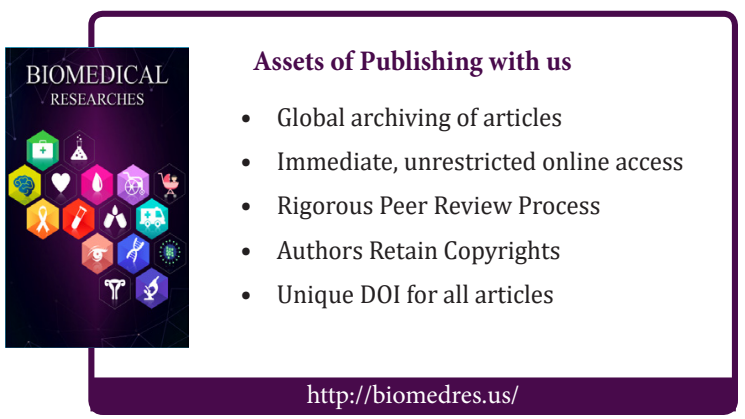

